\title{
ON HYERS-ULAM-RASSIAS STABILITY OF A QUADRATIC FUNCTIONAL EQUATION
}

\section{ICK-SoOn Chang, Eun Hwi LeE AND HARK-MAHN KIM}

Abstract. In this paper, we investigate the Hyers-Ulam-Rassias stability of a new quadratic functional equation

$$
\begin{aligned}
f(x+ & y+z+w)+2 f(x)+2 f(y)+2 f(z)+2 f(w) \\
& =f(x+y)+f(y+z)+f(z+x)+f(x+w)+f(y+w)+f(z+w) .
\end{aligned}
$$

Moreover, the stability results will be applied to the study of an interesting asymptotic property of the quadratic function.

Mathematics subject classification (2000): 39B52, 39B72.

Key words and phrases: Hyers-Ulam-Rassias stability; quadratic functional equation.

\section{REFERENCES}

[1] J. ACZel And J. Dhombres, Functional Equations in Several Variables, Cambridge Univ. Press (1989).

[2] C. Borelli, On Hyers-Ulam stability for a class of functional equations, Aequationes Math. 54 (1997), 74-86.

[3] P. W. CHOlEWA, Remarks on the stability of functional equations, Aequationes Math. 27 (1984), $76-86$.

[4] S. CZERWIK, On the stability of the quadratic mapping in normed spaces, Abh. Math. Sem. Univ. Hamburg 62 (1992), 59-64.

[5] D. H. Hyers, On the stability of the linear functional equation, Proc. Natl. Acad. Sci. 27 (1941), 222-224.

[6] D. H. Hyers AND TH. M. RASsiAs, Approximate homomorphisms, Aequationes Math 44 (1992), $125-153$.

[7] K. W. JUN AND Y. H. LEE, On the Hyers-Ulam-Rassias stability of a pexiderized quadratic inequality, Math. Inequal. Appl. 4(1) (2001), 93-118.

[8] S. M. JunG, On the Hyers-Ulam stability of the functional equations that have the quadratic property, J. Math. Anal. Appl. 222 (1998), 126-137.

[9] S. M. Jung, On the Hyers-Ulam-Rassias stability of a quadratic functional equation, J. Math. Anal. Appl. 232 (1999), 384-393.

[10] PL. KannapPan, Quadratic functional equation and inner product spaces, Results Math. 27 (1995), 368-372.

[11] J. C. PARnAmi And H. L. VASudeVA, On Jensen's functional equation, Aequationes Math. 43 (1992), 211-218.

[12] TH. M. RASsIAS, On the stability of the linear mapping in Banach spaces, Proc. Amer. Math. Soc. 72 (1978), 297-300.

[13] F. SKOF, Proprietà locali e approssimazione di operatori, Rend. Sem. Mat. Fis. Milano 53 (1983), 113-129.

[14] S. M. Ulam, Problems in Modern Mathematics, Chap. VI, Science ed., Wiley, New York (1960). 